\title{
SIMULAÇÃO NUMÉRICA DE VENTILADORES CENTRÍFUGOS COM VARIAÇÃ̃O DO TIPO DA VOLUTA: NORMAL E COM REENTRÂNCIA
}

\section{NUMERICAL SIMULATION OF CENTRIFUGAL FANS PERFORMANCE WITH VOLUTE TYPE CHANGE: NORMAL AND WITH INDENTATION}

\section{G. P. TOLEDO ${ }^{1, *}$ and H. M. P. ROSA ${ }^{2}$}

${ }^{1}$ Universidade Federal de Viçosa, Departamento de Engenharia de Produção e Mecânica, Viçosa, Minas Gerais, Brasil ${ }^{2}$ Universidade Federal de Viçosa, Departamento de Engenharia de Produção e Mecânica, Viçosa, Minas Gerais, Brasil

${ }^{*}$ Corresponding author. Universidade Federal de Viçosa, Departamento de Engenharia de Produção e Mecânica, Viçosa, Minas Gerais, Brasil, Telefone: +55 32 984235202

e-mail address: gabriela.toledo@ufv.br(G.P. Toledo).

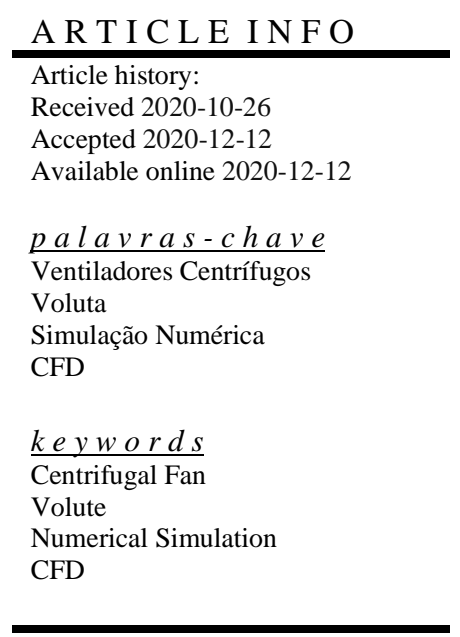

\begin{abstract}
A B S T R A C T
Centrifugal fans are machines widely used in many industry sectors. Due to its importance and the fact that the use of electric energy is a concern nowadays, the search for better performance in these machines is necessary. The objective is evaluate the influence of the volute type, normal and with indentation, on centrifugal fans performance through numerical simulation using CFD techniques. The comparative study between these two types of volutes is still scarce. For each type of volute, the mass flow was varied, and thus the difference pressure and yeld curves were set up. Pressure and velocity distributions were also analyzed. The results indicated a superiority of the normal volute.
\end{abstract}




\section{N O M E N C L A T UR A}

$\begin{array}{lll}\mathrm{b}_{4} & \text { Largura na entrada do rotor } & {[\mathrm{mm}]} \\ \mathrm{b}_{5} & \text { Largura na saída do rotor } & {[\mathrm{mm}]} \\ \mathrm{DP} & \text { Diferença de pressão } & {[\mathrm{Pa}]} \\ \mathrm{D}_{4} & \text { Diâmetro de entrada do rotor } & {[\mathrm{mm}]} \\ \mathrm{D}_{5} & \text { Diâmetro de saída do rotor } & {[\mathrm{mm}]} \\ \mathrm{e} & \text { Rugosidade } & {[\mu \mathrm{m}]} \\ \mathrm{l} & \text { Largura da voluta } & {[\mathrm{mm}]} \\ \dot{m} & \text { Vazão mássica } & {[\mathrm{kg} / \mathrm{s}]} \\ \mathrm{n} & \text { Rotação } & {[\mathrm{rpm}]} \\ \mathrm{P}_{\mathrm{H}} & \text { Potência hidráulica } & {[\mathrm{W}]} \\ \mathrm{P}_{\mathrm{e}} & \text { Pressão de entrada } & {[\mathrm{Pa}]} \\ \mathrm{P}_{\mathrm{E}} & \text { Potência de eixo } & {[\mathrm{W}]} \\ \mathrm{T} & \text { Torque } & {[\mathrm{N} . \mathrm{m}]} \\ \mathrm{T}_{\mathrm{t}} & \text { Torque total } & {[\mathrm{N} . \mathrm{m}]} \\ \beta_{4} & \text { Ângulo de entrada } & {[\mathrm{graus}]} \\ \beta_{5} & \text { Ângulo de saída } & {[\mathrm{graus}]} \\ \eta & \text { Rendimento } & {[\%]} \\ \rho & \text { Densidade do ar } & {\left[\mathrm{kg} / \mathrm{m}^{3}\right]} \\ \mathrm{BEP} & \text { Best Efficiency Point } & \end{array}$

\section{INTRODUÇÃO}

Máquinas de fluxo são máquinas que funcionam devido a interação do fluido com o sistema. Estas máquinas são representadas pelas bombas, turbinas e ventiladores. No caso de ventiladores e bombas a transferência de energia ocorre com a transformação de trabalho mecânico, pela rotação do eixo, em energia hidráulica.

Tais equipamentos estão presentes em diversas áreas da indústria e até mesmo no cotidiano das pessoas (Paramasivan et al., 2015), sendo aplicações mais conhecidas a ventilação de ambiente, bombeamento de água e produção de energia nas usinas hidrelétricas. Como envolvem geração ou consumo de energia elétrica, fica claro a demanda pela busca do aumento de eficiência destas máquinas.

Devido ao fato de que para estas máquinas pequenas alterações podem provocar variações positivas na eficiência, o uso de ferramentas de simulação numérica como o CFD (Computer Fluid Dynamic) tem sido largamente empregado por pesquisadores, tanto na indústria como na academia, uma vez que envolvem custos inferiores e demandam menor tempo em relação às montagens experimentais.
Bazani et al. (2011) propõem traçar estas curvas através da simulação numérica CFD. Indo mais além, Tsai e Wu (2007) projetaram e manufaturaram um protótipo de ventilador centrifugo visando comparar a simulação numérica com os resultados experimentais.

Buscando a relação entre eficiência e o fluxo na máquina, Siwek et al. (2014) realizaram um estudo numérico e experimental com o objetivo de determinar as distribuições de pressão, velocidades relativas e perfis de velocidade no rotor.

Rosa e Emerick (2018) utilizaram a ferramenta CFD para simular duas versões do rotor de uma bomba, uma com 6 pás e outra com 10, e avaliar a influência do número de pás sobre a energia transferida ao fluido e a distribuição de pressão.

Hariharan e Govardhan (2016) estudaram o aumento da eficiência em um ventilador centrífugo industrial comparando o uso de voluta de paredes paralelas com voluta retangular para quatro rotores de diâmetros distintos. Segundo os autores, a voluta é o ponto de partida para melhorar a performance de um ventilador devido ao fato de ser o elemento com menor desempenho em ventiladores centrífugos.

Lin e Tsai (2011) utilizaram um ventilador centrífugo com pás inclinadas para trás com objetivo de avaliar o desempenho de ventiladores centrífugos e propuseram alterações para melhorar a performance do ventilador.

O fator ruído interfere no rendimento de turbo máquinas, $\mathrm{Xu}$ e Mao (2016) realizaram um estudo experimental da utilização de metal esponjoso (estrutura metal-orgânica) com o objetivo de reduzir o ruído. Avaliando o mesmo fator, Jian et al. (2016) estudaram a ocorrência de ruído levando em consideração o efeito da voluta.

A maioria dos estudos realizados nesta área, tem como propósito a melhoria da eficiência. Buscam isso, alternando material, estudando o ruído, avaliando o uso de volutas alternativas. Neste contexto, este trabalho tem por objetivo fazer um estudo comparativo por meio de simulação CFD de duas versões de um ventilador centrífugo: com voluta normal e com voluta com reentrância.

\section{METODOLOGIA}

A metodologia adotada está exibida no fluxograma da Figura 1.

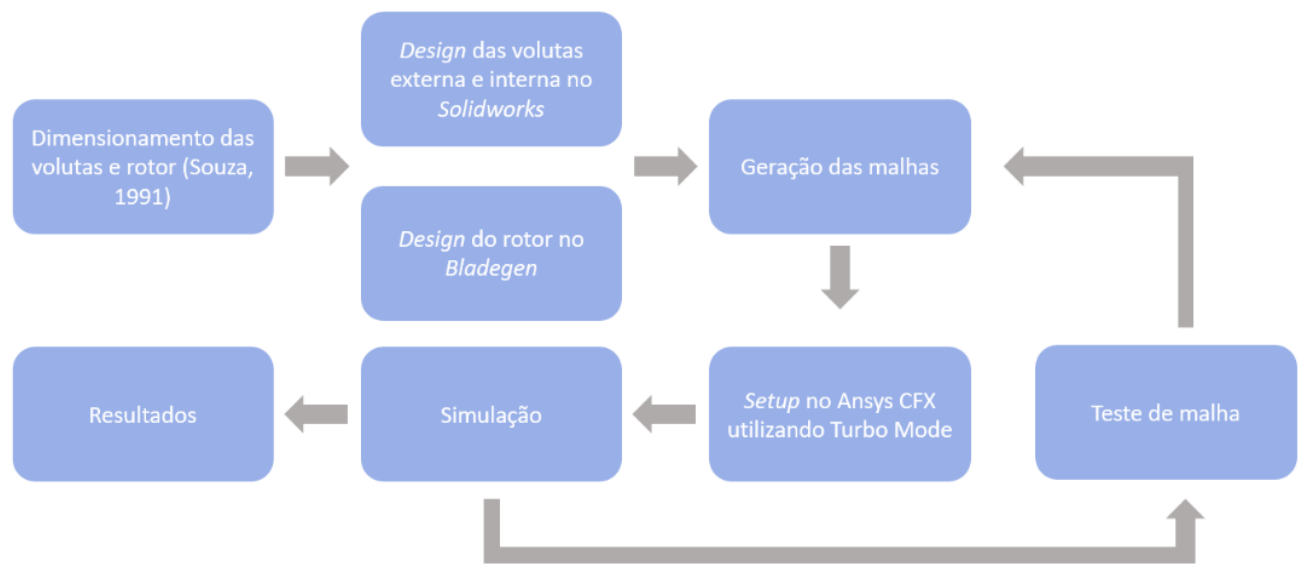

Figura 1 - Fluxograma da metodologia. 
As simulações realizadas para este trabalho, foram feitas utilizando um computador do Laboratório de Manufatura e Engenharia Assistida por Computador (LabCam) localizado no LABENGE da Universidade Federal de Viçosa (UFV). As principais características deste computador são mostradas na Tabela 1.

O dimensionamento das volutas e do rotor foi realizado a partir da metodologia descrita em Souza (1991) com o auxílio do software Excel® 2013, em que o ventilador foi projetado para a vazão mássica de $\dot{m}=0,1205 \mathrm{~kg} / \mathrm{s}$ na saída da voluta (outlet), para pressão de entrada de $\mathrm{Pe}=0 \mathrm{kPa}$ (inlet) e funcionando à velocidade angular de $\mathrm{n}=3550 \mathrm{rpm}$. Para $\mathrm{o}$ cálculo da espiral, a voluta foi dividida em 16 partes e os raios calculados se encontram na Tabela 2.

Tabela 1 - Características do computador utilizado.

\begin{tabular}{cc}
\hline Itens & Configuração \\
Processador & Intel Xeon $2,4 \mathrm{GHz}$ \\
Número de processadores & 12 \\
Memória RAM & $16 \mathrm{~Gb}$ \\
Disco rígido & $1 \mathrm{~Tb}$ \\
Sistema operacional & Windows 7 (64 bits) \\
Placa de vídeo & NVIDIA Quadro 600 - \\
& 1Gb DDR3
\end{tabular}

Tabela 2 - Raios utilizados para a espiral da voluta.

\begin{tabular}{|c|c|c|c|c|c|c|c|c|c|c|c|c|c|c|c|c|}
\hline $\mathrm{i}$ & 1 & 2 & 3 & 4 & 5 & 6 & 7 & 8 & 9 & 10 & 11 & 12 & 13 & 14 & 15 & 16 \\
\hline $\begin{array}{l}\mathrm{R}(\mathrm{i}) / \\
\mathrm{mm}\end{array}$ & 131 & 136 & 141 & 146 & 152 & 157 & 163 & 169 & 175 & 182 & 188 & 195 & 202 & 210 & 217 & 225 \\
\hline
\end{tabular}

As volutas obtidas, normal e com reentrância, estão ilustradas na Figura 2 e foram desenhadas com o software SolidWorks®. Ambas possuem largura constante de $125 \mathrm{~mm}$, dimensão na saída da voluta de 125 x $46,56 \mathrm{~mm}$ e a reentrância da voluta é de $8 \mathrm{~mm}$.

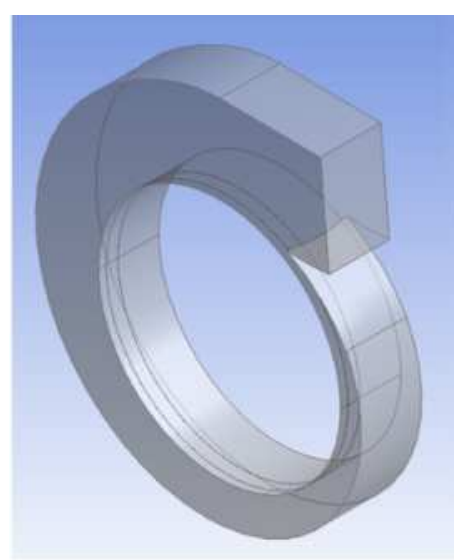

(a) Voluta normal

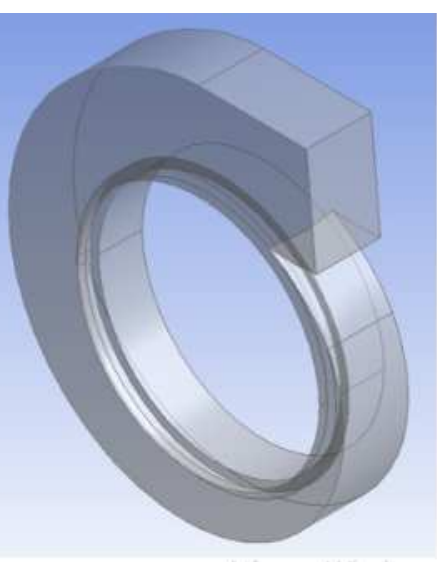

(b) Voluta com reentrância
O rotor calculado possui 11 pás e os demais dados geométricos obtidos se encontram na Tabela 3.

Tabela 3 - Dados geométricos calculados.

$\begin{array}{cc} & \text { Dimensão } \\ \mathrm{D}_{4} & 102,00 \mathrm{~mm} \\ \mathrm{D}_{5} & 241,20 \mathrm{~mm} \\ \mathrm{~b}_{4} & 27,00 \mathrm{~mm} \\ \mathrm{~b}_{5} & 12,00 \mathrm{~mm} \\ \beta_{4} & 30,35^{\circ} \\ \beta_{5} & 34,10^{\circ}\end{array}$

Com a posse destes dados, fez-se a modelagem do rotor no software BladeGen $\AA$, incluso no pacote ANSYS $®$ 15.0, obtendo a geometria representada na Figura 2 a para o corte longitudinal do rotor e na Figura $2 \mathrm{~b}$ que mostra uma vista $3 \mathrm{D}$ da pá e do canal de escoamento.

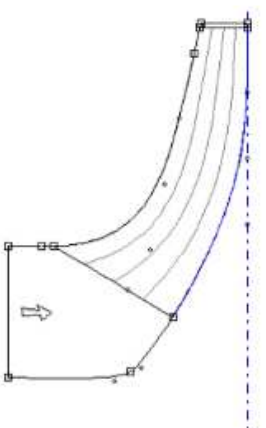

(a) Corte longitudinal

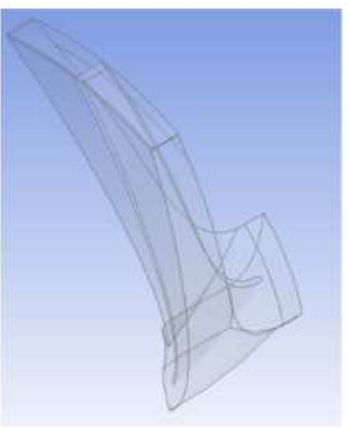

(b) Vista 3D
Figura 3 - Rotor projetado.

Todo o setup da simulação foi realizado com o software ANSYS® CFX 15.0. Este software resolve as equações de continuidade, energia e Navier-Stokes (Hariharan et al., 2016) e o erro residual (RMS) adotado foi de $10^{-4}$. Visando reduzir o tempo de simulação, foi simulado apenas uma pá do rotor, visto que o rotor possui geometria simétrica e devido a isto a simulação de uma pá pode ser reproduzida para as demais.

O fluido simulado foi o ar a $25{ }^{\circ} \mathrm{C}$ e densidade $\rho=1,184$ $\mathrm{kg} / \mathrm{m}^{3}$. O tipo de malha adotado neste trabalho foi a composta por elementos tetraédricos, devido sua versatilidade em geometrias complexas (Souza, 2011). Patil et al. (2018) utilizaram essa malha para simular o rotor com pás curvadas para trás com o objetivo de avaliar o efeito da folga da lingueta na performance de ventiladores centrífugos.

Para contemplar os efeitos da turbulência que ocorre no escoamento dentro do ventilador o ANSYS ${ }^{\circledR}$ CFX utiliza modelos de turbulência. O adotado neste trabalho foi o SST (Shear Stress Transport). O SST foi desenvolvido por Menter (1994), é um modelo híbrido que combina características dos modelos $\kappa-\varepsilon$ e $\kappa-\omega$. O algoritmo do $\kappa-\varepsilon$ fornece resultados mais acurados em regiões do escoamento distantes de paredes. Por outro lado, o do $\kappa-\omega$ foi concebido para computar melhor os fenômenos próximos à paredes. O modelo SST faz a junção dos dois através da função automática para tratamento de escoamento próximo de parede e é amplamente utilizado em simulações de ventiladores centrífugos (Azem et al., 2018). Utilizando como parâmetro de comparação a distância adimensional da parede, a função automática seleciona qual algoritmo utilizar, de forma que, nas regiões próximas à paredes, 
o $\kappa-\omega$ é empregado, e nas distantes, o $\kappa-\varepsilon$ (Shojaeefard, 2012; Paramasivam et al., 2017).

A condição Frozen Rotor foi adotada na interface rotorvoluta, que permite que as particularidades locais do escoamento sejam transportadas através dessa interface (ESSS). Foi adotada a condição de não deslizamento entre o fluido e a parede (Derakhshan et al., 2013; Zhu et al., 2016; Jung et al, 2016) e rugosidade desta de e $=50 \mu \mathrm{m}$, considerando como material o aço comercial (Fox et al., 2014)

No pós processamento dos dados, foram calculados o torque (T), para uma pá por meio da Equação 1, e a diferença de pressão no ventilador (DP) pela Equação 2:

$\mathrm{T}=$ torque_z()@Rotor Hub+torque_z()@Rotor Blade +torque_z()@Rotor Shroud

DP = massFlowAve(Total Pressure in Stn Frame)@Voluta Outlet -massFlowAve(Total Pressure in Stn Frame)@Rotor Inlet
O torque calculado é relativo a uma pá, desta forma o torque total $(\mathrm{Tt})$ pode ser obtido multiplicando o resultado anterior pelo número de pás, como mostra a Equação 3.

$\mathrm{T}_{\mathrm{t}}=\mathrm{T} * 11$

Desta forma, calculou-se a potência hidráulica $\left(\mathrm{P}_{\mathrm{H}}\right)$, potência de eixo $\left(P_{E}\right)$ e o rendimento $(\eta)$, pelas Equações 4,5 e 6 , respectivamente:

$\mathrm{P}_{\mathrm{H}}=D P * \frac{\dot{m}}{\rho}$
$\mathrm{P}_{\mathrm{E}}=\frac{2 * \pi * n * T_{t}}{60}$
$\eta=\frac{P_{H}}{P_{E}} * 100$

Com posse dessas informações, realizou-se o teste de malha variando o número total de elementos, como mostra a Figura 4.

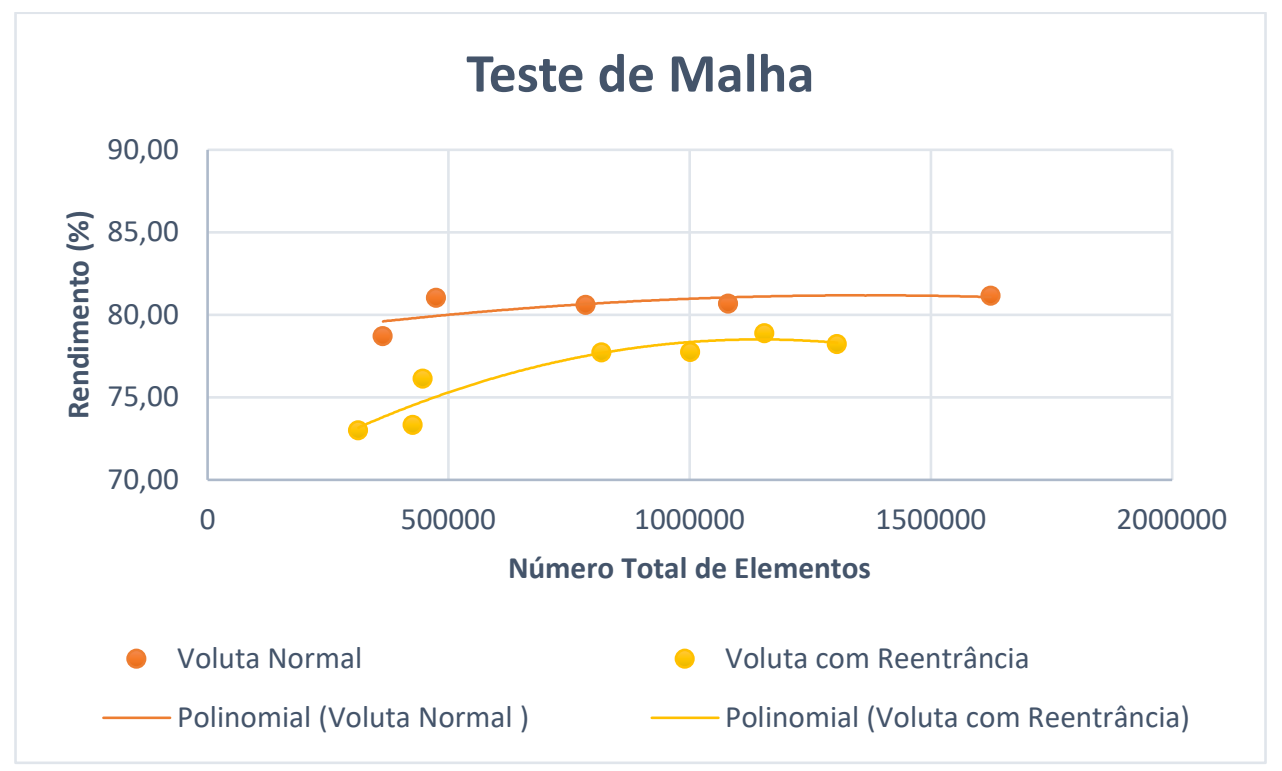

Figura 4 - Teste de malha.

Após análise da dependência de malha, foram selecionadas para o conjunto rotor + voluta, a de 783.840 elementos para o arranjo com voluta normal e a de 817.097 elementos para a configuração com voluta com reentrância. Ambas as configurações possuem orthogonal quality superior a 0,85 . As malhas da voluta podem ser visualizadas nas Figuras $5 \mathrm{a}$ e $5 b$.

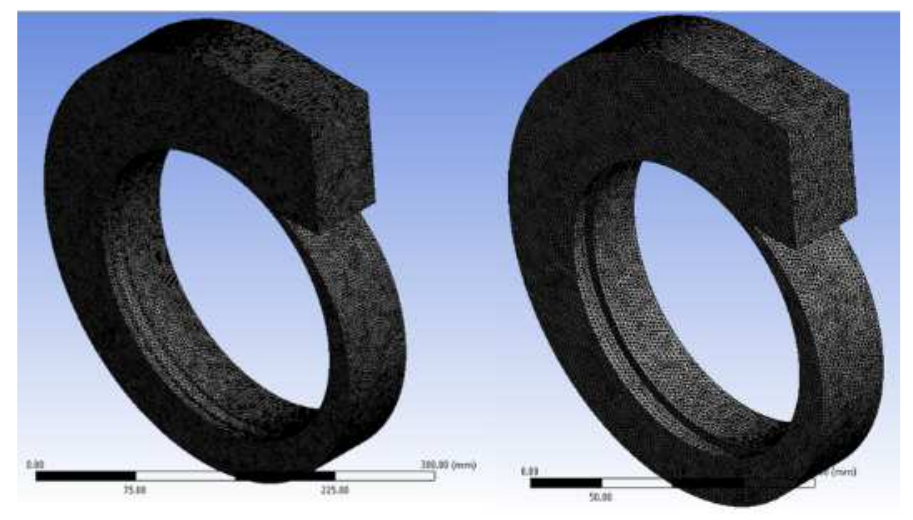

(a) Voluta normal

(b) Voluta com reentrância Figura 5 - Malhas selecionadas para as volutas. 
A malha selecionada para a pá do rotor pode ser observada na Figura 6.

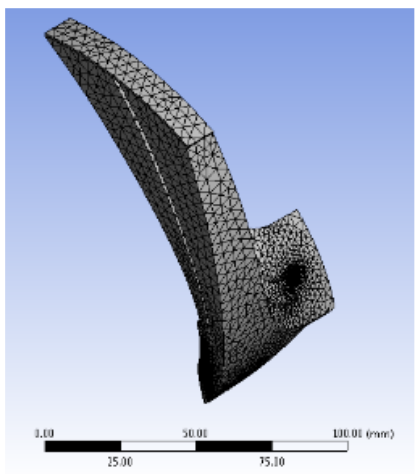

Figura 6 - Malha da pá do rotor.

\section{RESULTADOS E DISCUSSÕES}

Foram realizadas simulações para as porcentagens de $20,40,60,80,100,115$ e 130 da vazão nominal. Através destas, foram obtidos os dados da Tabela 4 .

Dado o exposto, é possível observar que o BEP (Best Efficiency Point) para o ventilador deste trabalho ocorre em $100 \%$ da vazão nominal com rendimento de $80,62 \%$ utilizando a voluta normal e em $80 \%$ da vazão nominal na voluta com reentrância com rendimento de
80,81\%. Na Figura 7, pode-se observar o gráfico comparativo da diferença de pressão em função da vazão para as duas volutas.

Tabela 4 - Dados obtidos através das simulações variando as vazões.

\begin{tabular}{ccccc|}
$\begin{array}{c}\text { Porcentagem } \\
\text { da Vazão }\end{array}$ & DP/ & $\boldsymbol{\eta} /$ & \multicolumn{2}{c|}{$\begin{array}{c}\text { Voluta com } \\
\text { Reentrância }\end{array}$} \\
Nominal & $\mathbf{P a}$ & $\%$ & $\mathbf{P a}$ & $\boldsymbol{\eta} /$ \\
\hline 20 & 1136 & 53,63 & 1067 & 58,29 \\
40 & 1157 & 64,05 & 1080 & 68,33 \\
60 & 1183 & 75,40 & 1072 & 77,25 \\
80 & 1171 & 80,35 & 974 & 80,81 \\
100 & 1020 & 80,62 & 799,9 & 77,75 \\
115 & 871,5 & 76,23 & 647,9 & 72,16 \\
130 & 699,8 & 70,00 & 462,7 & 60,48 \\
\end{tabular}

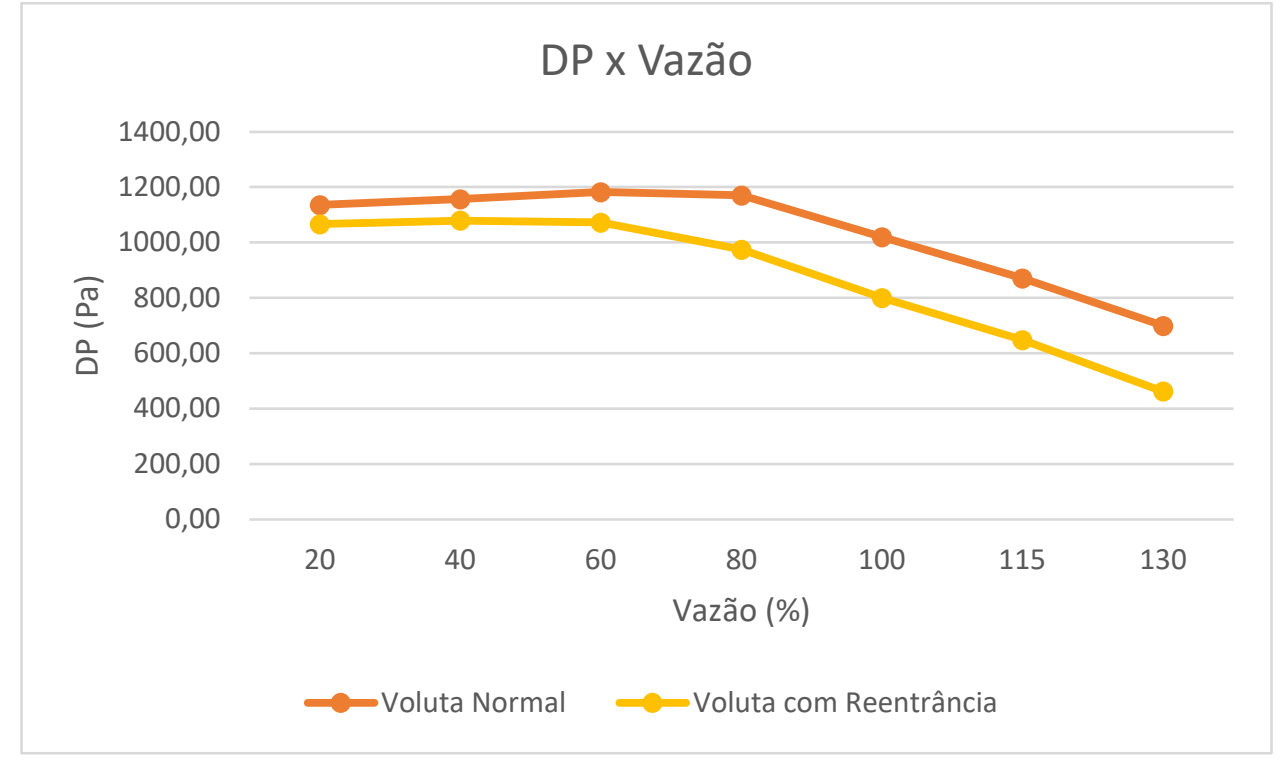

Figura 7 - Diferença de pressão em função da vazão.

O gráfico mostra que a voluta normal produz maior diferença de pressão entre a entrada e saída do volume de controle, o que indica que do ponto de vista de diferença de pressão o arranjo com voluta normal é mais vantajoso. O comportamento das curvas de rendimento (Figura 8) mostra que as curvas se cruzam no ponto de vazão $80 \%$ da nominal, sendo que para as vazões menores a voluta com reentrância apresenta maior rendimento, ocorrendo o oposto para as vazões maiores. 


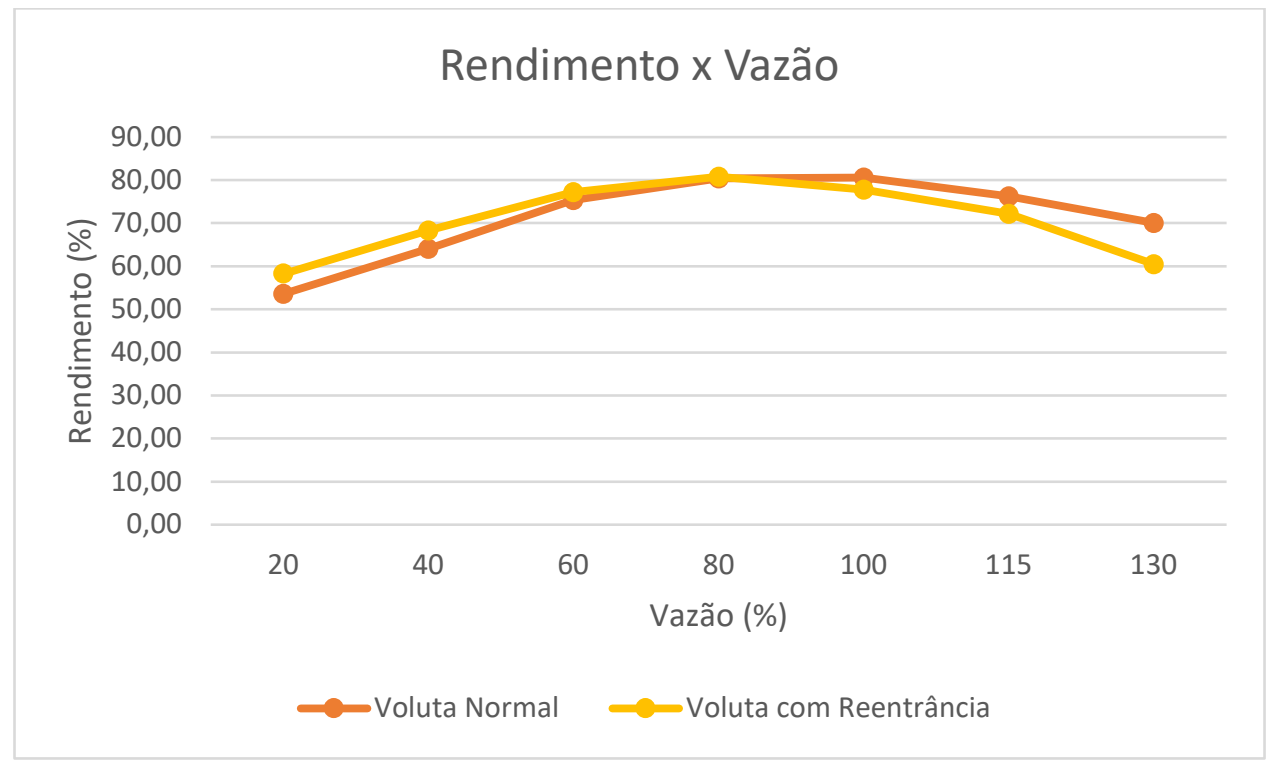

Figura 8 - Rendimento em função da vazão.

Em síntese, a comparação através da variação do rendimento

Nas Figuras 9 e 10, pode-se visualizar o contorno de da voluta com reentrância em relação à normal, para as diferentespressão estática no plano XY para as duas volutas analisadas. A vazões, pode ser observada na Tabela 4.

Tabela 4. Variação do rendimento entre as volutas.

\begin{tabular}{cc}
$\begin{array}{c}\text { Porcentagem da } \\
\text { Vazão }\end{array}$ & $\begin{array}{c}\text { Variação do Rendimento/ } \\
\text { \% }\end{array}$ \\
40 & 8,70 \\
60 & 6,69 \\
80 & 2,46 \\
100 & 0,57 \\
115 & $-3,56$ \\
130 & $-5,34$ \\
\hline
\end{tabular}
distribuição da pressão estática no rotor em ambas são semelhantes, o que era esperado, visto que o rotor é o mesmo. Nas volutas a diferença é maior. Na voluta normal (Fig. 9), a pressão é praticamente a mesma, com pequenas áreas de pressão mais baixa próximo à saída do rotor e maior na parte mais externa. Já na voluta com reentrância (Fig. 10) tem-se duas faixas de maior pressão na parte mais externa da voluta, essas faixas se iniciam próximo a lingueta da voluta. Em ambas, há uma pequena área de maior pressão na saída da voluta, também na região adjacente à lingueta; isso pode ocorrer devido a ação da pá do rotor que passa muito próxima à lingueta.

De acordo com a Tabela 4, a maior diferença entre rendimentos a favor da voluta normal ocorreu na vazão de $130 \%$ e foi de $13,6 \%$, e a favor da voluta com reentrância ocorreu na de $20 \%$, e foi de $8,7 \%$. Para a vazão de $100 \%$ a diferença foi de $3,56 \%$ a favor da voluta normal. Estes dados indicam que a voluta normal é mais vantajosa em termos de eficiência, pois além de apresentar melhor rendimento para o ponto nominal, também apresenta para pontos onde a potência consumida é maior, ao passo que a voluta com reentrância apresenta melhores rendimentos para vazões onde a potência consumida é menor. Logo, do ponto de vista de energia consumida, a voluta normal é superior.

Para $100 \%$ da vazão nominal, pode-se observar os contornos de pressão, contornos de velocidade e vetores velocidade em dois planos diferentes: um plano transversal

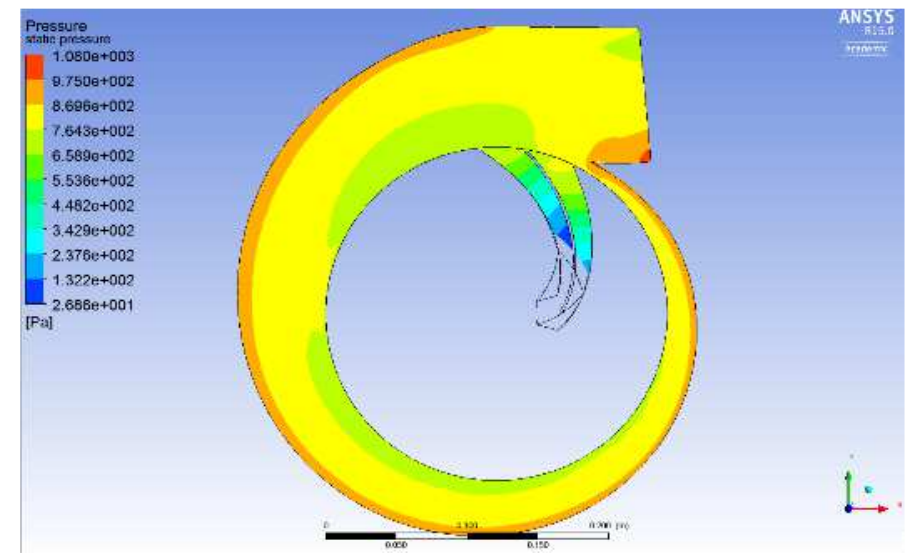

Figura 9 - Contorno de pressão estática no plano XY da voluta normal. um plano longitudinal (YZ). 


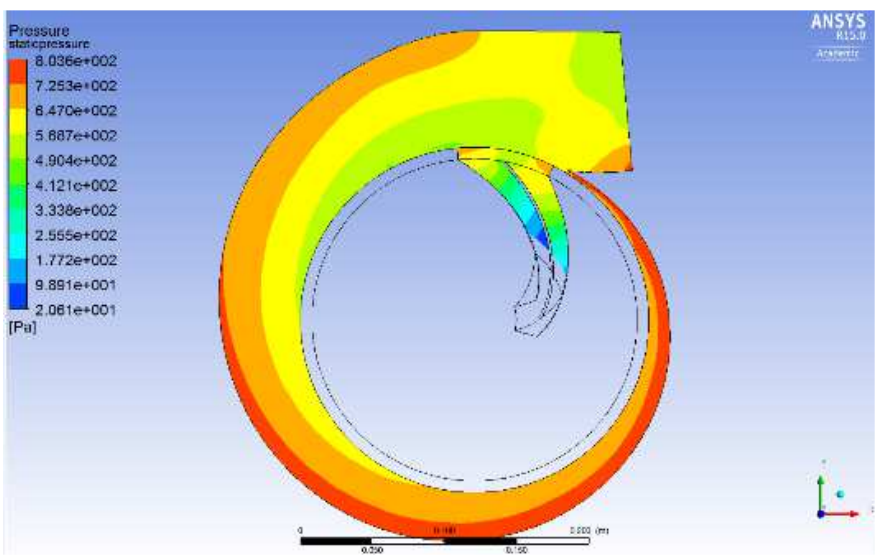

Figura 10 - Contorno de pressão estática plano XY da voluta com reentrância.

Nas figuras 11 e 12, tem-se o contorno de pressão estática no plano YZ para as volutas normal e com reentrância respectivamente. Para a voluta normal (Figura 11), percebe-se uma área de maior pressão na parte superior da área de saída da voluta, o que não ocorre para a voluta com reentrância (Figura 12). Em ambas, as zonas de menor pressão ocorrem próximo ao rotor e vão aumentando gradualmente até o extremo da voluta. É importante ressaltar a escala da graduação de cores, visto que para a voluta normal, os valores são maiores que para a outra. Um ponto interessante a observar, é que a distribuição da pressão na voluta com reentrância ocorre mais uniformemente que na voluta normal.

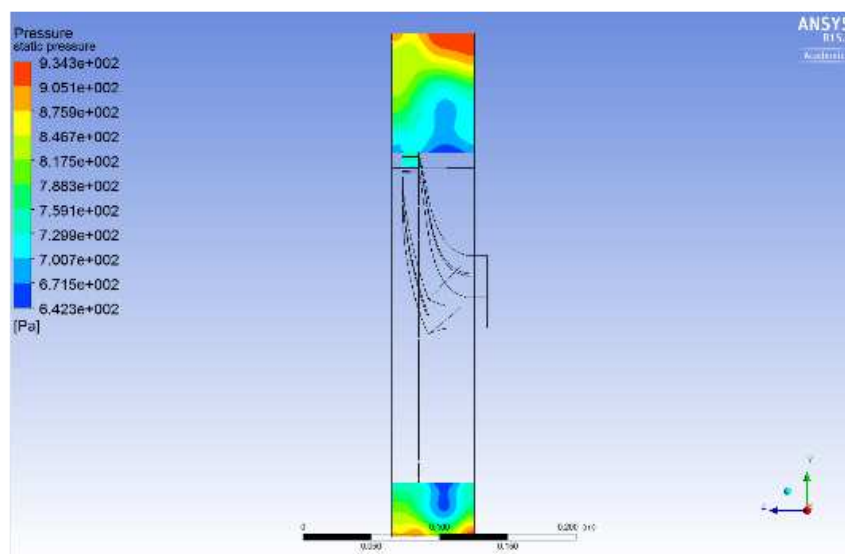

Figura 11 - Contorno de pressão estática plano YZ da voluta normal.

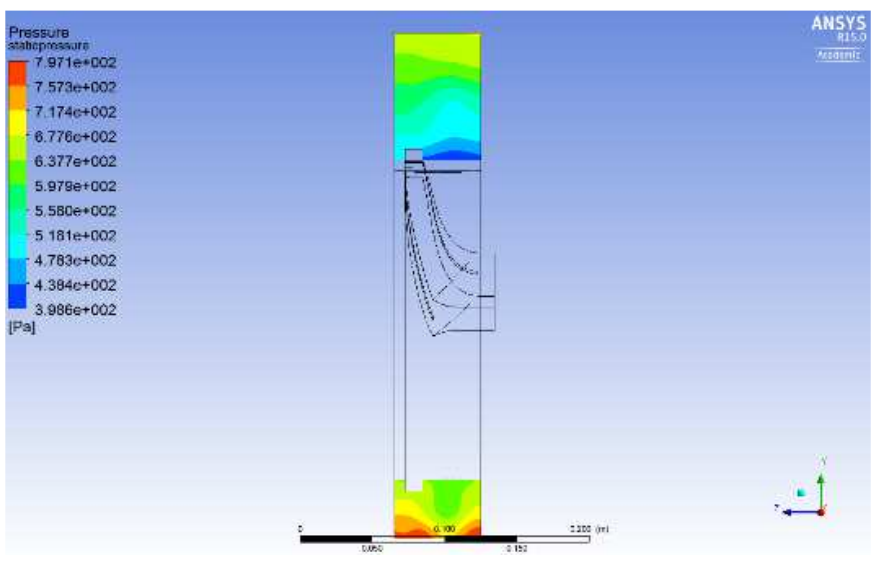

Figura 12 - Contorno de pressão estática plano YZ da voluta com reentrância.
Nas Figuras 13 e 14, observa-se o contorno de velocidade para as duas volutas no plano XY. Como esperado, a velocidade mínima ocorre na parede onde $\mathrm{v}=0$, decorrente da condição de não-deslizamento. Para a voluta normal (Figura 13) a velocidade máxima ocorre na parte mais próximas ao centro e com mais áreas de maior velocidade ao comparar com a voluta com reentrância (Figura 14). Essa maior velocidade do fluido na voluta normal, pode ser um indicativo de maior vibração nos ventiladores com este tipo de voluta.

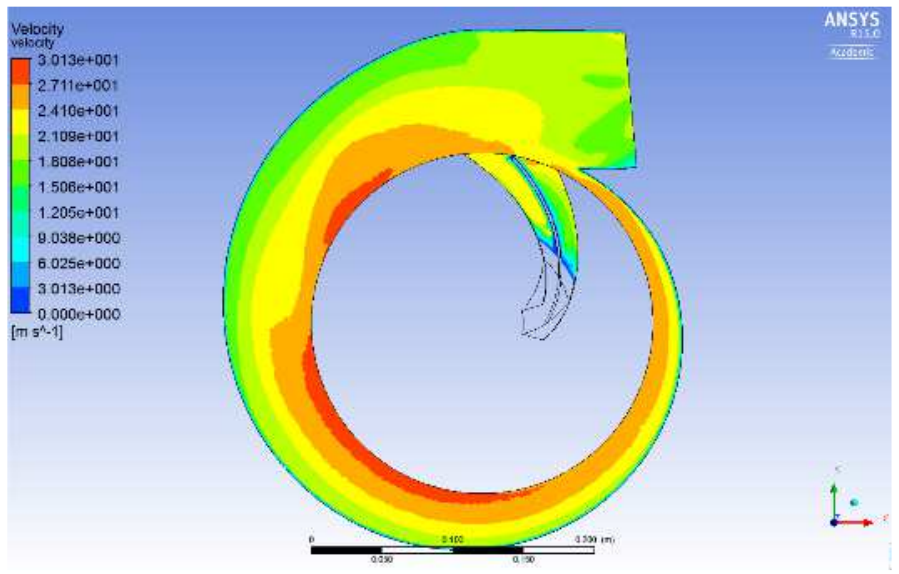

Figura 13 - Contorno de velocidade no plano XY da voluta normal.

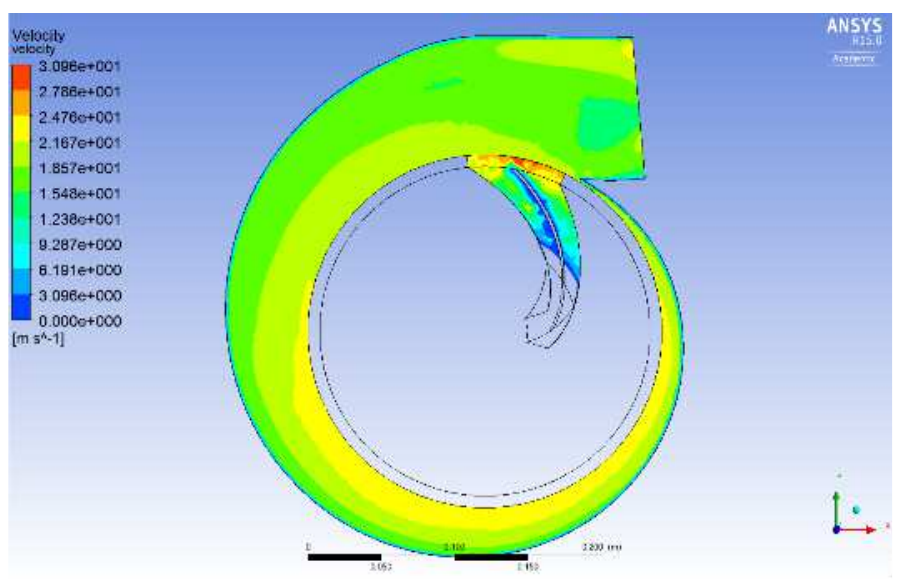

Figura 14 - Contorno de velocidade no plano XY da voluta com reentrância.

Nas Figuras 15 e 16, observa-se o contorno de velocidade para as duas volutas no plano $\mathrm{YZ}$ passando pelo centro da voluta. Para o ventilador com voluta normal (Figura 15), há apenas pequenas áreas de maior velocidade, enquanto na voluta com reentrância (Figura 16) há uma área maior na parte superior da voluta. Em ambas, o contorno de velocidade se constrói a partir de uma área de velocidade máxima e reduz até chegar a zero na parede. 


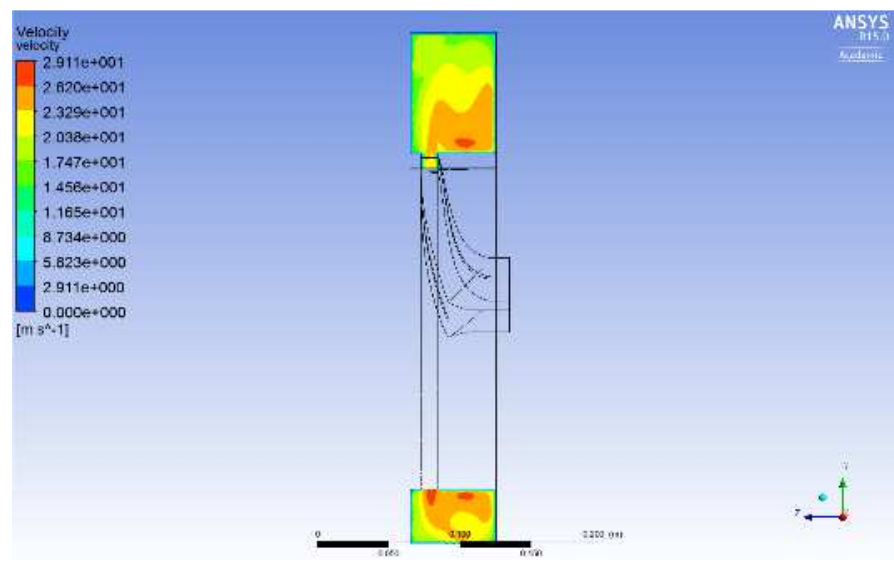

Figura 15 - Contorno de velocidade no plano YZ da voluta normal.

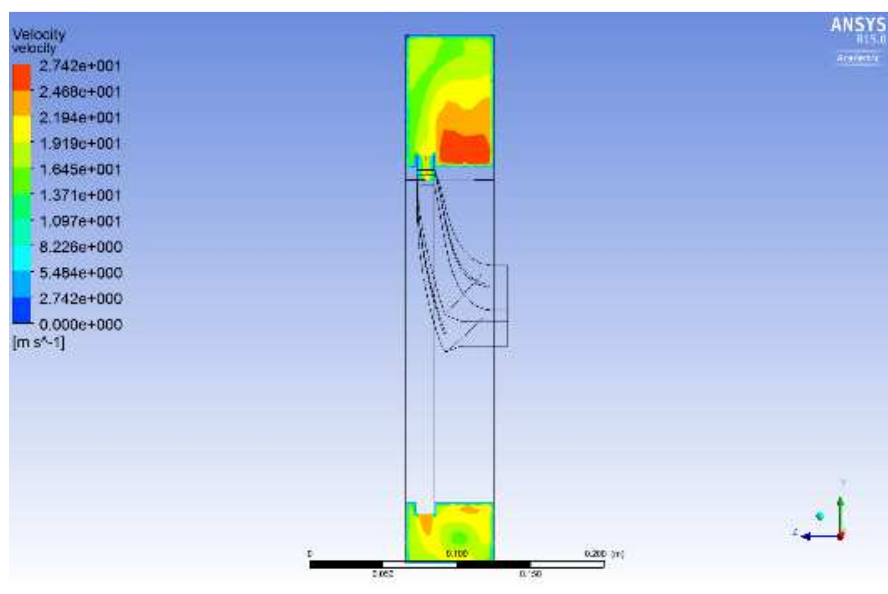

Figura 16 - Contorno de velocidade no plano YZ da voluta com reentrância.

Nas Figuras 17 e 18, é mostrado os vetores velocidade para as volutas no plano XY. Pode-se observar que para as duas volutas os vetores de maior velocidade ocorrem na saída do rotor.

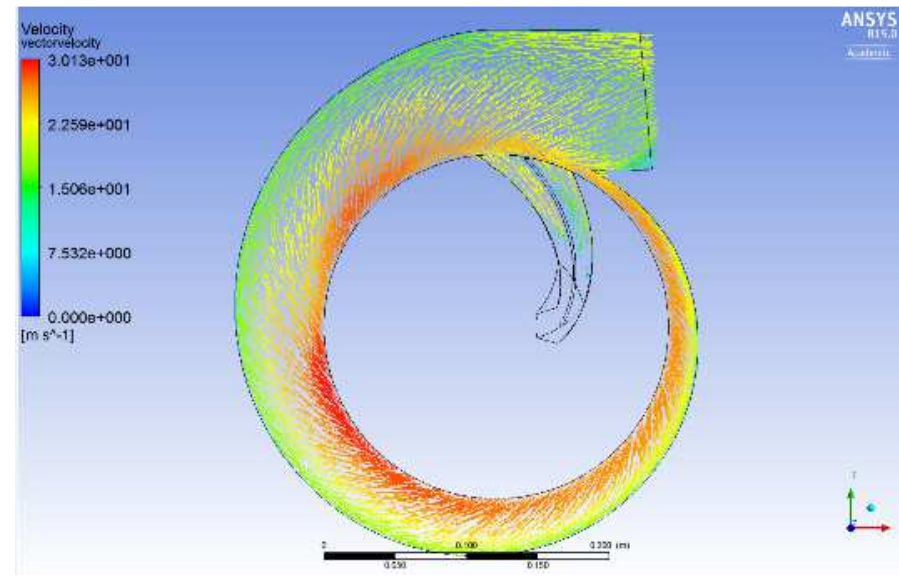

Figura 17 - Vetor velocidade no plano XY da voluta normal.

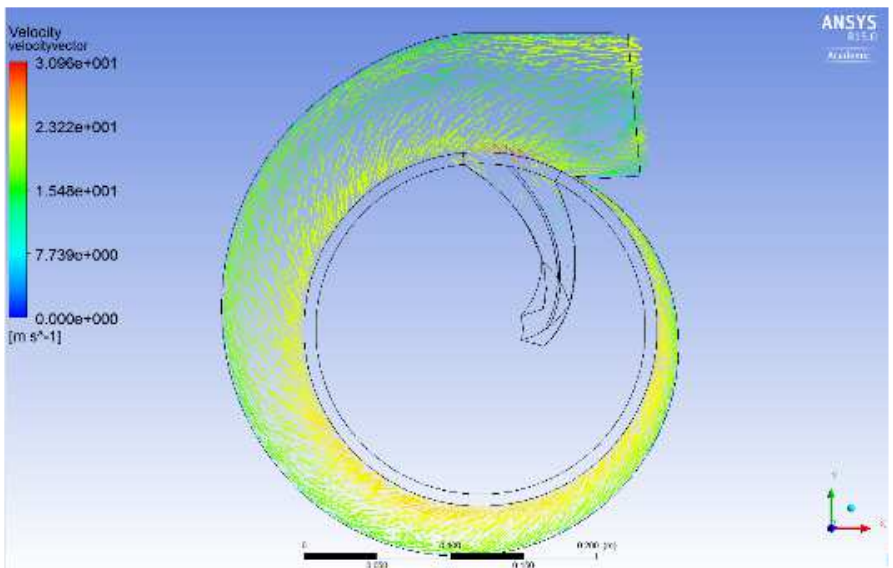

Figura 18 - Vetor velocidade no plano XY da voluta com reentrância.

Nas Figuras 19 e 20, é mostrado os vetores velocidade para as volutas no plano YZ. Em ambas as figuras, pode-se observar que o vetor que sai do rotor é normal ao mesmo. $\mathrm{Na}$ Figura 19, há uma área de recirculação na parte inferior e na parte superior há duas áreas de recirculação, a maior em sentido horário e a menor, no canto superior esquerdo, no sentido antihorário. Esta recirculação é uma característica de escoamentos dentro de volutas de ventilador e bombas (Sedille, 1967). Na Figura 20, não há esse movimento no sentido anti-horário na parte superior, os vetores dessa zona saem normalmente à página. Como nas demais figuras, a velocidade no geral é menor na voluta com reentrância.

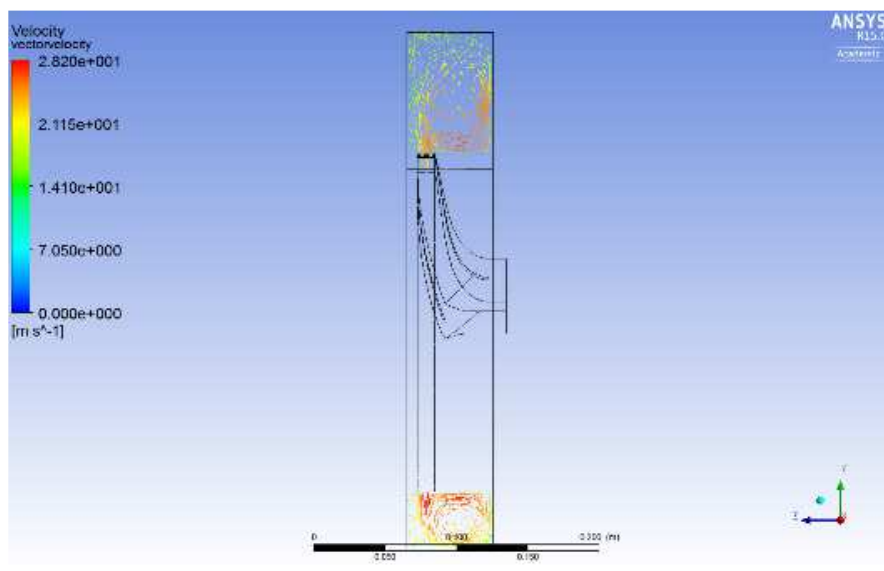

Figura 19 - Vetor velocidade no plano YZ da voluta normal.

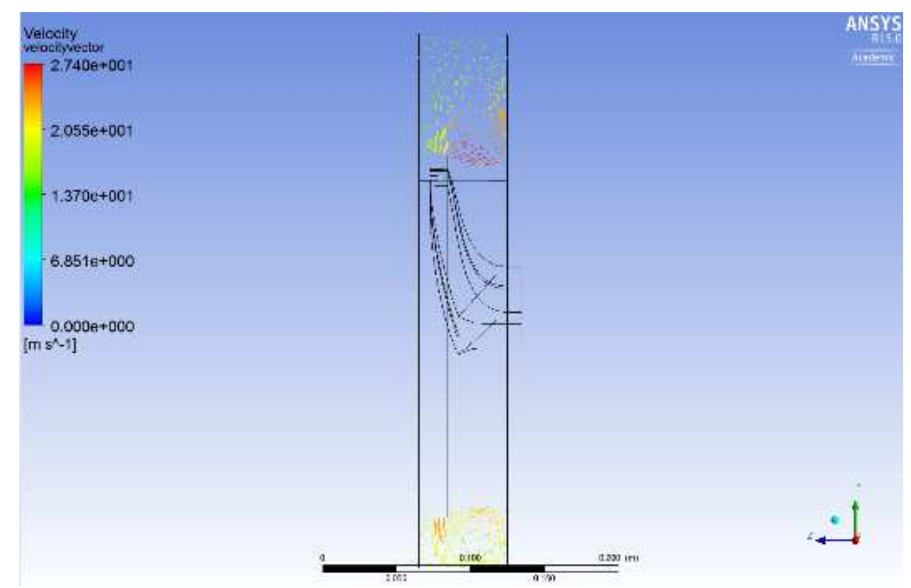

Figura 20 - Vetor velocidade no plano YZ da voluta com reentrância. 


\section{CONCLUSÃO}

Neste trabalho é realizado um estudo comparativo entre dois projetos de ventiladores centrífugos: 1) com voluta normal e 2) com voluta com reentrância. As seguintes conclusões podem ser feitas:

- A voluta com reentrância resulta em menor diferença de pressão entre a entrada e a saída do ventilador.

- Os valores de rendimento máximo foram praticamente os mesmos, $80,62 \%$ contra $80,81 \%$, para as duas volutas. Entretanto, o BEP ocorreu para vazões diferentes: vazão de $100 \%$ da nominal para a voluta normal e de $80 \%$ para a voluta com reentrância.

- Do ponto de vista da diferença de pressão e rendimento o projeto com voluta normal se mostrou mais vantajoso.

- O comportamento da pressão estática e velocidade nas volutas é diferente, tanto em termos de valores, quanto de distribuição espacial, sendo que a voluta com reentrância apresentou distribuição mais uniforme para os dois parâmetros, ao passo que a voluta normal apresentou valores maiores, também para os dois parâmetros.

\section{AGRADECIMENTOS}

Os autores agradecem a FAPEMIG pela provisão de financiamento de bolsa de Iniciação Científica.

\section{REFERÊNCIAS}

AZEM, A.; MATHIS, P.; STUTE, F.; HOFFMANN, M.; MÜLLER, D.; HETZEL, G. Efficiency increase of free running centrifugal fans through a pressure regain unit used in an air handling unit. Energy \& Buildings, v. 165, p. 321-327. 2018.

BAZANI, M. A.; PASCHOALINI, A. T.; HONORIO, H. T. Simulação numérica de um ventilador centrífugo. In: $10^{\mathrm{a}}$ CONFERÊNCIA BRASILEIRA DE DINÂMICA, CONTROLE E APLICAÇÕES, 2011. p. 188-191.

DERAKHSHAN, S.; POURMAHDAVI, M.; ABDOLAHNEJAD, E.; REIHANI, A.; OJAGHI, A. Numerical shape optimization of a centrifugal pump impeller using artificial bee colony algorithm. Computers \& Fluids, v. 81, p. 145-151. 2013.

ESSS. Interface entre domínios rotativos: modelos para a simulação de turbomáquinas. Disponível em: $<$ https://www.esss.co/blog/interface-entre-dominiosrotativos-modelos-para-a-simulacao-de-

turbomaquinas/>. Acesso em: 13 de jul. 2020.

FOX, R. W.; MCDONALD, A.T.; PRITCHARD, P. J.; LEYLEIGIAN, J. C. Introdução à mecânica dos fluidos. LTC, 2014.

HARIHARAN, C.; GOVARDHAN, M. Improving performance of an industrial centrifugal blower with parallel wall volutes. Applied Thermal Engineering, v.
109, part A, p. 53-64. 2016.

JIAN, C.; YUAN, H.; LI, G.; CANXING, W.; LIU, C.; YUANRUI, L. Aerodynamic noise prediction of a centrifugal fan considering the volute effect using IBEM. Applied Acoustics, v. 132, p. 182-190. 2018.

JUNG, U.; KIM, J.; KIM, J.; PARK, C.; JUN, S.; CHOI, Y. Optimum design of diffuser in a small high-speed centrifugal fan using CFD \& DOE. Journal of Mechanical Science and Technology, v. 30, n. 3, p. 1171-1184. 2016.

LIN, S.; TSAI, M. An integrated performance analysis for a backward-inclined centrifugal fan. Computers \& Fluids, v. 56, p. 24-38. 2011.

MENTER, F. R. Two-equation eddy-viscosity turbulence models for engineering applications. AIAA-Journal, v. 32, n. 8, p. 1598-1605. 1994.

PARAMASIVAM, K.; RAJOO, S.; ROMAGNOLI, A. Suppression of tonal noise in a centrifugal fan using guide vanes. Journal of Sound and Vibration, v. 357, p. 95-106. 2015.

PARAMASIVAM, K.; RAJOO, S.; ROMAGNOLI, A.; YAHYA, W. J. Tonal noise prediction in a small high speed centrifugal fan and experimental validation. Applied Acoustics, v. 125, p. 59-70. 2017.

PATIL, S. R.; CHAVAN, S. T.; JADHAV, N. S.; VADGERI, S. S. Effect of volute tongue clearance variation on performance of centrifugal blower by numerical and experimental analysis. Materials Today: Proceedings, v. 5, p. 3883-3894. 2018.

ROSA, H. M. P.; EMERICK, B. S. CFD simulation of a centrifugal pump impeller with variations of a number of blades. The Journal of Engineering and Exact Sciences, v. 4, p. 220-224. 2018.

SEDILLE, M. Turbumachines hydrauliques et thermiques. Tome 2. Paris: Masson \& Cie Éditeurs, 1967. 572p.

SHOJAEEFARD, M. H.; EHGHAGHI, M. P.; FALLAHIAN, M. A.; BEGLARI, M. Numerical study of the effects of some geometric characteristics of a centrifugal pump impeller that pumps a viscous fluid. Computer \& Fluids, v. 60, p. 61-70. 2012.

SIWEK, T.; GORSKI, J.; FORTUNA, S. Numerical and experimental study of a centrifugal fan flow structur and their relationship with machine efficiency. Polish Journal of Environmental Studies, p. 2359-2364. 2014.

SOUZA, Z. Dimensionamento de máquinas de fluxo. São Paulo: Edgard Blucher LTDA, 1991.

SOUZA, Z. Projetos de máquinas de fluxo - TOMO I. Rio de Janeiro: Editora Interciência, 2011.

TSAI, B. J.; WU, C. L. Investigation of a miniature centrifugal fan. Applied Thermal Engineering, v. 27, p. 229-239. 2007.

XU, C.; MAO, Y. Experimental investigation of metal foam for controlling centrifugal fan noise. Applied Acoustics, v. 104, p. 182-192. 2016.

ZHU, X.; LI, G.; JIANG, W.; FU, L. Experimental and numerical investigation on application of half vane diffusers for centrifugal pump. International Communications in Heat and Mass Transfer, v. 79, p. 114-127. 2016. 